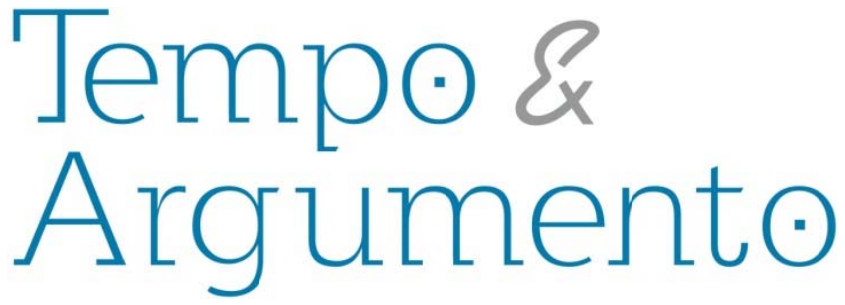

\title{
Reflexões sobre o Humor Contemporâneo - uma entrevista com Oscar Steimberg
}

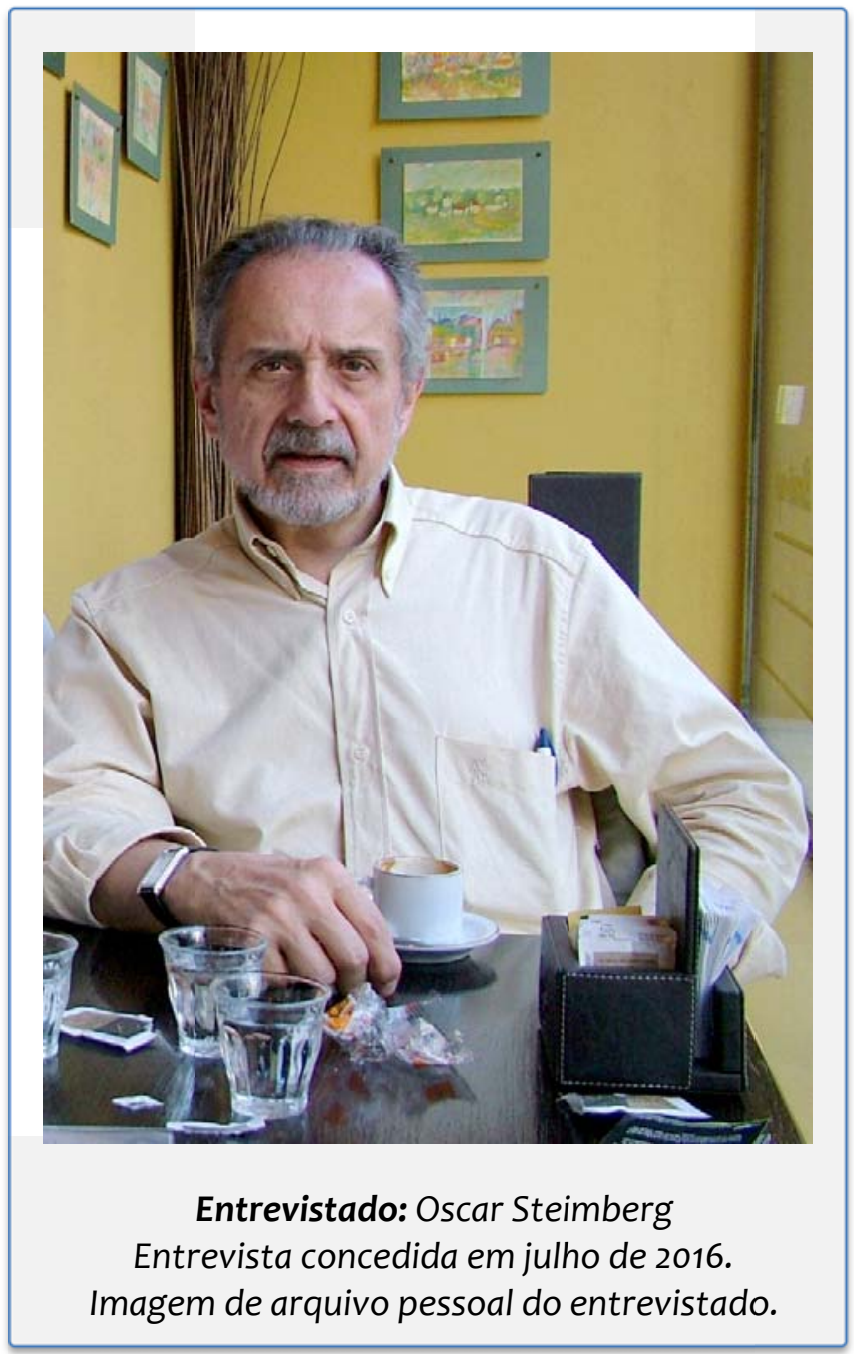

Entrevistadoras

\section{Conceição Pires}

Doutora em História pela Universidade Federal Fluminense. Professora da Universidade Federal do Estado do Rio de Janeiro.

Brasil

conceicao.pires@uol.com.br

\section{Mara Burkart}

Doutora em Ciencias Sociais pela Universidade de Buenos Aires.

Pesquisadora do Conselho Nacional de Investigações Ciientíficas e Técnicas.

Argentina

burkartmara@gmail.com

\section{Para citar esta entrevista:}

STEIMBERG, Oscar. Reflexões sobre o Humor Contemporâneo - Uma entrevista com Oscar Steimberg. [Entrevista realizada em xx de julho, 2016]. Revista Tempo e Argumento, Florianópolis, v. 8 , n. 18, p. 463 - 469, maio/ago. 2016. Entrevistadoras: Conceição Pires, Mara Burkart. 


\section{Entrevistado}

Oscar Steimberg é um dos mais destacados acadêmicos argentinos. Semiólogo e escritor, foi Presidente da Asociación Argentina de Semiótica, é professor emérito da Universidad de Buenos Aires (UBA) e, atualmente, diretor de Posgrado da Área Transdepartamental de Crítica de Artes, da Universidad Nacional de las Artes (IUNA). Autodeclarado discípulo de Oscar Masotta e Eliseo Veron, foi um dos primeiros intelectuais argentinos a desenvolver reflexões sobre Patoruzú, Mafalda, Langostino e Isidor. Suas pesquisas sobre linguagens artísticas e midiáticas foram publicadas a partir de 1968 em livros e revistas por editoras da Argentina, Brasil, México, Estados Unidos, França, Itália, Alemanha e Bélgica. Entre seus livros destacam-se: Cuerpo sin armazón, Editores Dos, Buenos Aires, 1970; Leyendo historietas: estilos y sentidos en un "arte menor", Ed. Nueva Visión, Buenos Aires, 1977; Majestad, etc., poesía, libro, Ediciones Tierra Baldía, Buenos Aires, I980; La recepción del género, UNLZ, Buenos Aires, 1988; Estilo de época y comunicación mediática, en colaboración con Oscar Traversa, Ed. Atuel, Buenos Aires, 1997; Semiótica de los medios masivos, primera edición, 1993 e última edição corrigida, Ed. Atuel, Buenos Aires, 2000; Gardel y la zarina, Libros de tierra firme, Buenos Aires, 1995; Figuración de Gabino Betinotti, Editorial Sudamericana, Buenos Aires, 1999; El viaje y la utopía, edición de trabajos de investigadores de las universidades de Buenos Aires y Bologna, en colaboración con Vita Fortunati, Atuel, 2001; El pretexto del sueño, Buenos Aires, Ed. Santiago Arcos, 2005; Posible patria y otros versos, El suri porfiado ediciones, Buenos Aires, 2007; El volver de las imágenes. Mirar, guardar, perder, compilación con Oscar Traversa y Marita Soto, La Crujía, Buenos Aires, 2008; Semióticas. Las semióticas de los géneros, de los estilos, de la transposición, Buenos Aires, Eterna Cadencia Editora, 2013; e Leyendo historietas. Textos sobre relatos visuales y humor gráfico, Buenos Aires, Eterna Cadencia Editora, 2013. 
Tempo e Argumento - Ud. fue uno de los precursores de los estudios relativos a las historietas y el humor gráfico en la Argentina y discute esa cuestión también a nivel internacional. ¿Cómo Ud. caracteriza esa área de investigación en la actualidad? ¿Ud. percibe alguna restricción en el uso del término "intelectuales" para pensar a los humoristas como productores de cultura y conocimiento?

Oscar Steimberg - En cuanto a la primera pregunta: creo que se trata de un campo de trabajo que no ha dejado de ganar en complejidad y nuevo interés en las últimas décadas. Digo “complejidad” porque los cambios se han producido no solamente en rasgos de estilo, repertorio temático, y procedimientos de relato, sino también en lo que respecta a los espacios de publicación y difusión y a sus articulaciones con otros medios y géneros. En general, ha crecido la propuesta de compartir una dimensión lúdica: se juega con las posibilidades de la comicidad y el humor en relación con los personajes con vida pública, y también con las representaciones de lo que serían los habitantes tipo de la ciudad contemporánea. En la Argentina, pueden encontrarse ejemplos en todos los medios de difusión masiva. Tomando como casos el de un diario más que tradicional y más que centenario, como La Nación, y otro con juegos de modernidad y sobremodernidad desde la tapa, como Página 12, se advierte la ausencia en ambos de cierto tipo de historietas que en otro tiempo eran comunes en las secciones correspondientes, como las de aventuras. $Y$ en ambos ocurre que la historieta "costumbrista" haya pasado a presentar, podríamos decir, un costumbrismo con componentes de búsqueda psicológica novedosa, no cerrada, como ocurre en los episodios de humoristas como Liniers, en La Nación, y Rep, en Página 12.

En cuanto se está haciendo con eso, a la manera de cómo se lo investiga y se lo discute, podríamos decir que ha habido un crecimiento cualitativo en la investigación y el ensayo dedicados a este campo de producción cultural: especialmente en el ámbito universitario, hay búsquedas de permanente interés, llevadas adelante por gente cada vez más numerosa y más informada. Y en las publicaciones mismas, el lugar del metadiscurso se ha convertido en una suerte de 
complemento permanente del de la historieta y el humor. En el ámbito internacional, es difícil ahora encontrar una revista de superhéroes que no conceda un lugar importante a los prólogos, a los comentarios o la discusión con los lectores. En cuanto al emplazamiento social de los que producen el nuevo humor gráfico, creo que es realmente difícil definir el lugar social que están ocupando. Por supuesto, hay humoristas de los que es difícil suponer que no han ocupado ese lugar, como Quino, si se trata de establecer quiénes contribuyeron a definir en la Argentina lo que se entiende por clase media (creo que ningún sociólogo rechazaría la vecindad de ese co-investigador).

Tempo e Argumento - Su abordaje sobre el humor y las historietas tienen una característica fundamentalmente multidisciplinaria. ¿Esto estaría relacionado específicamente con su formación o sería un imperativo de su objeto de estudio?

Oscar Steimberg - Creo que está relacionado con mis objetos de estudio... pero también con la manera que me ha tocado de elegir esos objetos. Siempre atendí a la manera de decir o de contar, tanto como a lo que se decía o contaba. Mi interés por la historieta empezó tarde, cuando estudiaba con Masotta y apareció el tema de la historieta como un objeto cultural que había empezado a interesar a los artistas de vanguardia por su rara vida social, tomado a la vez como soporte de relatos, de imágenes, de jergas... Y en mi caso influía también el hecho de que siempre me ocurrió producir un tipo de literatura o de poesía con definiciones borrosas de lenguaje o de género: mi primer libro literario era de relatos, pero mi idea era que apareciera ilustrado. Y más tarde escribí poesía para ser cantada (como tango, como canción en la versión teatral de cuentos populares...) Pero de todos modos es difícil estudiar la historieta o el humor gráfico sin partir de más de una disciplina para ese estudio. Son objetos multilingüísticos, o plurisemióticos... 
Tempo e Argumento - En sus libros y artículos, la relación entre humor y política está colocada como telón de fondo. ¿Ud. considera esta unión irrevocable? A partir de esta cuestión, ¿cómo podríamos pensar la violencia contra el otro presente en el humor contemporáneo?

Oscar Steimberg - Podría decirse que en el humor gráfico la política está siempre acechando para ocupar la escena. Las situaciones de comicidad en que puede ser representado uno u otro personaje social siempre tendrán en alguna instancia que ver con la problemática de sus relaciones sociales. Y la política existe en tanto modos y prácticas de esas relaciones. Esto puede estar explicitado, o no, en el discurso acompañante. Pero si un personaje aparece como un adulto-niño, y otro aparece como un adulto de tiempo completo que además piensa a partir de un pesimismo radical y universal, por ejemplo, la instancia política del sentido de sus comportamientos estará siempre actuando aunque no se explicite: se implicarán ideas acerca de los roles sociales, de lo que las instituciones permiten en relación con el desempeño de esos roles, de lo que puede o no puede políticamente decirse acerca de los otros...

Tempo e Argumento - Leyendo Historietas que fue publicado originalmente en 1977 y se convirtió en un referente insoslayable para el estudio sobre el tema. ¿Qué cambió de su mirada teórica desde entonces? O tal vez sea mejor preguntar, ¿qué permanece de su comprensión sobre el tema?

Oscar Steimberg - Gracias, creo que de la perspectiva que manejaba entonces se mantiene, por ejemplo, un modo de leer o mirar la historieta y el humor gráfico siempre de manera provisoria, yo creo que, más que en otros géneros, en los que trabajan con recursos plurales de lenguaje, las lecturas deben proponerse siempre como provisorias. Agregar dibujo al chiste o la cita o la reflexión verbal es asociar posibilidades de sentido que quedarán inevitablemente abiertas. Alguna vez tuve un programa de radio sobre historietas, en el que se hablaba de lo que podía quedar de la historieta o el humor gráfico cuando eso no se veía; creo que aunque no ocurra 
ese cambio de soporte, los sentidos de la historieta y el humor gráfico siguen siendo provisorios y cambiantes, porque en cada instancia de retorno a esos dibujos y letras se elige un fragmento del objeto, una posibilidad momentánea de cierre. Con respecto a eso, sigo pensando igual. Lo que se fue agregando puede que sea una mayor apertura, hoy, al reconocimiento de lo que en la historieta o el humor gráfico ha pasado a mostrarse como provisoriedad permanente: hoy en las historietas de superhéroes los protagonistas dudan de todo, empezando por su misión y por las relaciones con amigos y enemigos, y en los dibujos de humor político puede colarse una crueldad para con el personaje que el humorista ha demostrado seguir y amar.

Tempo e Argumento - ¿Cómo caracterizaría la producción humorística e historietística actual? ¿Encuentra algo innovador en ella? Si la respuesta es afirmativa, ¿qué cosas?

Oscar Steimberg - Sí, yo creo que ha crecido por un lado, lo que hablábamos acerca del reconocimiento del carácter provisorio de los sentidos adjudicados a los personajes y sus entornos; pero tan importante como eso es la condición a menudo desatada de, creo que no hay otra manera de decirlo, la experimentación artística. A lo largo de su extensísima trayectoria de humorista gráfico, Hermenegildo Sábat mantuvo siempre (o más bien mantuvo en crecimiento permanente) la asociación abierta de elementos, digamos, propositivos en sus dibujos (relacionados con humoradas traducibles verbalmente), junto a motivos y elementos de difícil o imposible definición. Durante la presidencia Menem, empezó en una época a poner junto a la imagen del presidente a un pequeño león rampante, que podría ser pensar en algún rasgo batallador del caricaturizado. Pero después de algún tiempo, la pequeña fiera empezó a aparecer junto a otros personajes, o más bien en cualquier lado. Se podría pensar que no era, entonces, que se estaba aludiendo a alguna condición psicológico-política del personaje, sino, a algún dato del momento político. ¿O a nada en especial? Como en otras obras de arte, los componentes del juego estético pueden actualmente negarse a cerrar sentido en algún nivel. Y seguir ahí, con tanto derecho como la textura que se deja ver, o no, en una pintura al óleo. 
Tempo e Argumento -¿Cuál es su proyecto actual? ¿A qué se dedica actualmente?

Oscar Steimberg - Arrancando con el tema de la historieta, la revista Entre Líneas, que interrumpió su aparición después del primer número y se está tratando de que vuelva, se espera que con una centralización en el tema de los bordes actuales de la historieta y, más genéricamente, de la narrativa dibujada (algo bastante atendido actualmente...), que coordinamos inicialmente con un equipo más grande.

-Nuevas puestas en escena de Figuración de Gabino Betinotti, un libro de, digamos, meta-tangos que musicalizó Pablo Di Liscia, ilustró Oscar Grillo y canta y actúa Brian Chambouleyron, y que ahora fue traducido al francés por Didier Coste y editado por Bernardo Schiavetta en una versión bilingüe de lo mejor.

-La puesta en escena de la teatralización de una canción popular irlandesa, idea de Francisco Kröpfl que se estrenará en la sala de experimentación musical del Teatro Colón en septiembre.

-La continuidad de dos carreras de crítica y difusión de las artes en la Universidad Nacional de las Artes, y, como siempre, las materias de post grado que doy en la UNA y en la facultad de Ciencias Sociales de la Universidad de Buenos Aires.

-Y la continuidad, siempre interrumpida, de las escrituras de poesía y ensayo, las de poesía mezcladas en parte con los proyectos escénicos y las de ensayo conectadas con la investigación en las cátedras de UNA y UBA, por un lado, y por otro con pedidos de participación en proyectos comunes, “intelectuales", políticos o artísticos (podría decirse). 